\title{
ORIGINAL
}

Y. López · J. A. Páramo · J. R. Valentí F. Pardo

R. Montes - E. Rocha

\section{Hemostatic markers in surgery: \\ a different fibrinolytic activity may be of pathophysiological significance in orthopedic versus abdominal surgery}

Received: 10 September $1997 /$ Accepted: 24 October 1997

\begin{abstract}
Without prophylaxis, patients subjected to major abdominal surgery have a risk of deep vein thrombosis of approximately $30 \%$, while the rate varies between $40 \%$ and $60 \%$ in orthopedic surgery. The reasons for this discrepancy are not completely understood. The present study was designed to compare the pre-and postoperative behavior of different coagulation and fibrinolysis parameters in patients undergoing both types of surgery, receiving low molecular weight heparin prophylaxis. Samples were taken before operation and on postoperative days 1,3 , and 7 . The following parameters were assessed: prothrombin fragment $1+2$, thrombin-antithrombin III complexes, fibrinopeptide $A$, tissue plasminogen activator, plasminogen activator inhibitor, plasmin- $\alpha_{2}$-antiplasmin complexes, and fibrin degradation products. We found a significant increase in the clotting markers postoperatively compared with preoperative values $(P<0.05)$, both in abdominal and orthopedic surgery, indicating a marked hemostatic activation which remained until postoperative day 7 . A significant increase in plasminogen activator inhibitor $(P<0.01)$ and a decrease in tissue plasminogen activator and plasmin- $\alpha_{2}$-antiplasmin complexes was also observed early
\end{abstract}

Y. López · J. A. Páramo · R. Montes · E. Rocha

Laboratory of Vascular Biology and Thrombosis Research,

University Clinic, University of Navarra,

Pamplona, Spain

J. A. Páramo · E. Rocha (区)

Hematology Service, University Clinic,

Avda. Pio XIIs/n, P. O. 4109.

E-31080 Pamplona, Spain

\section{J. R. Valentí}

Department of Orthopedics. University Clinic.

School of Medicine, University of Navarra,

Pamplona, Spain

F. Pardo

Department of General Surgery, University Clinic,

School of Medicine. University of Navarra,

Pamplona, Spain after operation. The plasminogen activator inhibitor activity decreased, while tissue plasminogen activator and plasmin- $\alpha_{2}$-antiplasmin levels increased significantly on days 3 and $7(P<0.05)$. Fibrin degradation products significantly increased throughout the postoperative period $(P<0.01)$. Preoperatively, we found higher plasminogen activator inhibitor activity and lower tissue plasminogen activator and plasmin- $\alpha_{2}$-antiplasmin complexes $(P<0.05)$ in patients undergoing hip replacement compared with abdominal surgery. Fibrin degradation products were also significantly lower on postoperative day 3 in patients undergoing hip replacement $(P<0.01)$. We suggest that the lower preoperative fibrinolytic activation observed in patients undergoing orthopedic surgery compared with abdominal surgery might have pathophysiological consequences. Our results also indicate that the hemostatic activation persists beyond the 7 th postoperative day despite prophylaxis.

Key words Surgery Clotting activation - Fibrinolysis

\section{Introduction}

During surgery, several factors such as venous stasis, vascular damage, and hemostatic changes may predispose to venous thrombosis in the lower extremities, leading to pulmonary embolism (PE) $[1,2]$. The incidence of deep vein thrombosis (DVT) after abdominal surgery in patients over 40 years varies between $10 \%$ and $30 \%$, while fatal PE has been reported in $0.5 \%-1 \%$ if no prophylaxis is used. Following major elective orthopedic surgery, more than $50 \%$ of patients will develop DVT, and approximately $3 \%-5 \%$ develop symptomatic $P E$, which remains the major cause of postoperative death $(0.5 \%-2 \%)[3,4]$. A considerable risk for DVT still remains (12\%-30\%), despite prophylaxis treatment $[5-8]$. To date, the factors contributing to the higher DVT incidence after orthopedic compared with abdominal surgery are not well established. Advanced age, prolonged bed rest, and major tissue injury, with subsequent changes in the coagulation and fibrinolytic mecha- 
nisms, could explain some of the observed differences between the types of surgery $[9,10]$.

Advances in our knowledge of the biochemistry of hemostasis have led to the development of sensitive and specific assays to identify prethrombotic states. These include activation peptides and enzyme-inhibitor complexes released during the activation of the coagulation and fibrinolytic systems. Prothrombin fragment $1+2(F 1+2)$, thrombin-antithrombin complexes (TAT), and fibrinopeptide A (FPA) are sensitive markers of thrombin formation and subsequently of clotting activation, whereas tissue-type plasminogen activator (t-PA), its inhibitor (PAI-1), plasmin-antiplasmin complexes (PAP), and fibrin degradation products (FDP) are useful for detecting an imbalance in the fibrinolytic mechanism $[11-13]$.

The aim of this study was to investigate whether differences in the pre- and postoperative plasma levels of several hemostatic activation markers could explain the higher thrombotic risk associated with orthopedic versus abdominal surgery in patients receiving low molecular weight heparin prophylaxis.

\section{Patients and methods}

Patients

Thirty patients ( 20 males, 10 females) subjected to major abdominal surgery, with a mean age of $54.4 \pm 11.6$ years (range 29-71), and 25 patients ( 15 males, 10 females) undergoing total hip replacement, with a mean age of $60.8 \pm 12.6$ years (range $39-80$ ), were included in the study. Indications for abdominal surgery were as follows: colon malignancy $(n=12)$, gastric malignancy $(n=7)$, cholecystectomy $(n=9)$, endometrium adenocarcinoma $(n=1)$, and hepatectomy $(n=1)$.

All patients received preoperatively low molecular weight heparin in doses adjusted to the thrombotic risk until postoperative day 7 : Fragmin (Pharmacia. Sweden) 2.500 U anti $\mathrm{Xa} / \mathrm{d}$ in patients undergoing abdominal surgery and Enoxaparin (Rhône Poulenc Rorer, France) $40 \mathrm{mg}$ in those undergoing hip replacement. The prophylaxis continued for 7 days or until discharge from hospital. Patients with a past history of a bleeding diathesis, thromboembolism within the past 3 months, or anticoagulant use in the previous 6 weeks were excluded from the study. Oral informed consent was obtained from all patients.

\section{Blood collection}

Blood samples were drawn before operation and on postoperative days 1,3 , and 7 . Venous blood was collected between 8 and 9 a. m., with patients at rest, in siliconized vacutainer tubes containing $0.13 \mathrm{M}$ trisodium citrate. Samples were kept on ice until centrifugation at $3,000 \mathrm{~g}$ for $15 \mathrm{~min}$. Aliquots of platelet-poor plasma were stored at $-70^{\circ} \mathrm{C}$. For $t$-PA determination, blood was collected in Stabilyte tubes (Biopool, Sweden) in order to avoid inhibitor interference. All preoperative samples were taken before prophylaxis administration.

\section{Assays}

Prothrombin $\mathrm{Fl}+2$ was assayed by ELISA, using the commercial Enzygnost $\mathrm{Fl}+2$ (Behringwerke, Germany) [14]. TAT were measured using the ELISA kit Enzygnost TAT (Behringwerke) [15]. FPA was measured with the ELISA FPA kit (Hemodiagnostica-Stago, France), which is a competitive enzyme immunoassay [16].

t-PA was determined using the Coatest BIA tPA kit (Chromogenix, Sweden), a bioimmunoassay which determines free t-PA [17]. Briefly, $50 \mu$ t of acidified sample was applied to the wells of a microtiter plate coated with a monoclonal anti t-PA antibody which does not block the active site of t-PA, so its activity can be measured in a spectrophotometer by adding a chromogenic substrate for plasmin.

PAI-1 was measured by an amidolytic assay, using the Coatest PAI kit (Chromogenix) [18]. PAP were measured with the ELISA previously described in our laboratory by Montes et al. [19]. FDP were measured with the Fibrinostika FDP kit (Organon Teknika, The Nederlands), with a specific anti D-dimer monoclonal antibody [20].

\section{Statistical analysis}

Mean values and standard errors were calculated. The two-tail Wilcoxon signed rank test was used for the comparison of post- and preoperative samples. To test for significant differences between abdominal and orthopedic surgery, the Mann-Whitney U test was used. A value of $P<0.05$ was considered significant.

\section{Results}

The study included 55 patients of both sexes who underwent abdominal surgery $(n=30)$ and total hip replacement $(n=25)$, with no significant differences in the mean age between the groups. Samples were taken preoperatively and on postoperative days 1,3 , and 7 to assess different coagulation and fibrinolysis parameters.

Preoperatively, the levels of the different clotting markers were slightly increased in orthopedic compared with abdominal surgery patients, although no significant differences were found. However, the preoperative PAI- 1 activity was significantly higher $(P<0.05)$, while t-PA activity and PAP complexes were lower $(P<0.05)$ in patients undergoing hip replacement compared with abdominal surgery (Table 1). FDP were more reduced in orthopedic patients, although without significant differences compared with the abdominal group $(P=0.07)$.

Figure 1 shows the postoperative evolution of the different clotting activation markers in patients undergoing abdominal and orthopedic surgery in relation to preopera-

Table 1 Comparison of preoperative levels of hemostatic markers in surgical patients (mean \pm SEM) $(F l+2$ prothrombin fragment $1+2$, TAT thrombin-antithrombin complexes, FPA fibrinopeptide A, $t$-PA tissue plasminogen activator, $P A I-1$ plasminogen activator inhibitor, $P A P$ plasmin-antiplasmin complexes, $F D P$ fibrin degradation products)

\begin{tabular}{lccl}
\hline Parameters & $\begin{array}{l}\text { Abdominal } \\
\text { surgery }\end{array}$ & $\begin{array}{l}\text { Orthopedic } \\
\text { surgery }\end{array}$ & $P$ \\
\hline Fl $+2(\mathrm{nmol} / \mathrm{l})$ & $1.26 \pm 0.10$ & $1.56 \pm 0.19$ & $\mathrm{NS}$ \\
$\mathrm{TAT}(\mu \mathrm{g} / \mathrm{l})$ & $4.55 \pm 0.77$ & $6.53 \pm 1.90$ & $\mathrm{NS}$ \\
$\mathrm{FPA}(\mu \mathrm{g} / \mathrm{l})$ & $1.28 \pm 0.10$ & $1.66 \pm 0.21$ & $\mathrm{NS}$ \\
$\mathrm{t}-\mathrm{PA}(\mathrm{U} / \mathrm{ml})$ & $0.28 \pm 0.04$ & $0.15 \pm 0.03$ & $<0.05$ \\
PAI- $(\mathrm{U} / \mathrm{ml})$ & $15.96 \pm 1.71$ & $20.36 \pm 2.49$ & $<0.05$ \\
PAP $(\mu \mathrm{g} / \mathrm{l})$ & $507.59 \pm 37.29$ & $320.23 \pm 29.22$ & $<0.001$ \\
FDP $(\mu \mathrm{g} / \mathrm{l})$ & $585.37 \pm 103.83$ & $365.68 \pm 48.44$ & $\mathrm{NS}$ \\
\hline
\end{tabular}




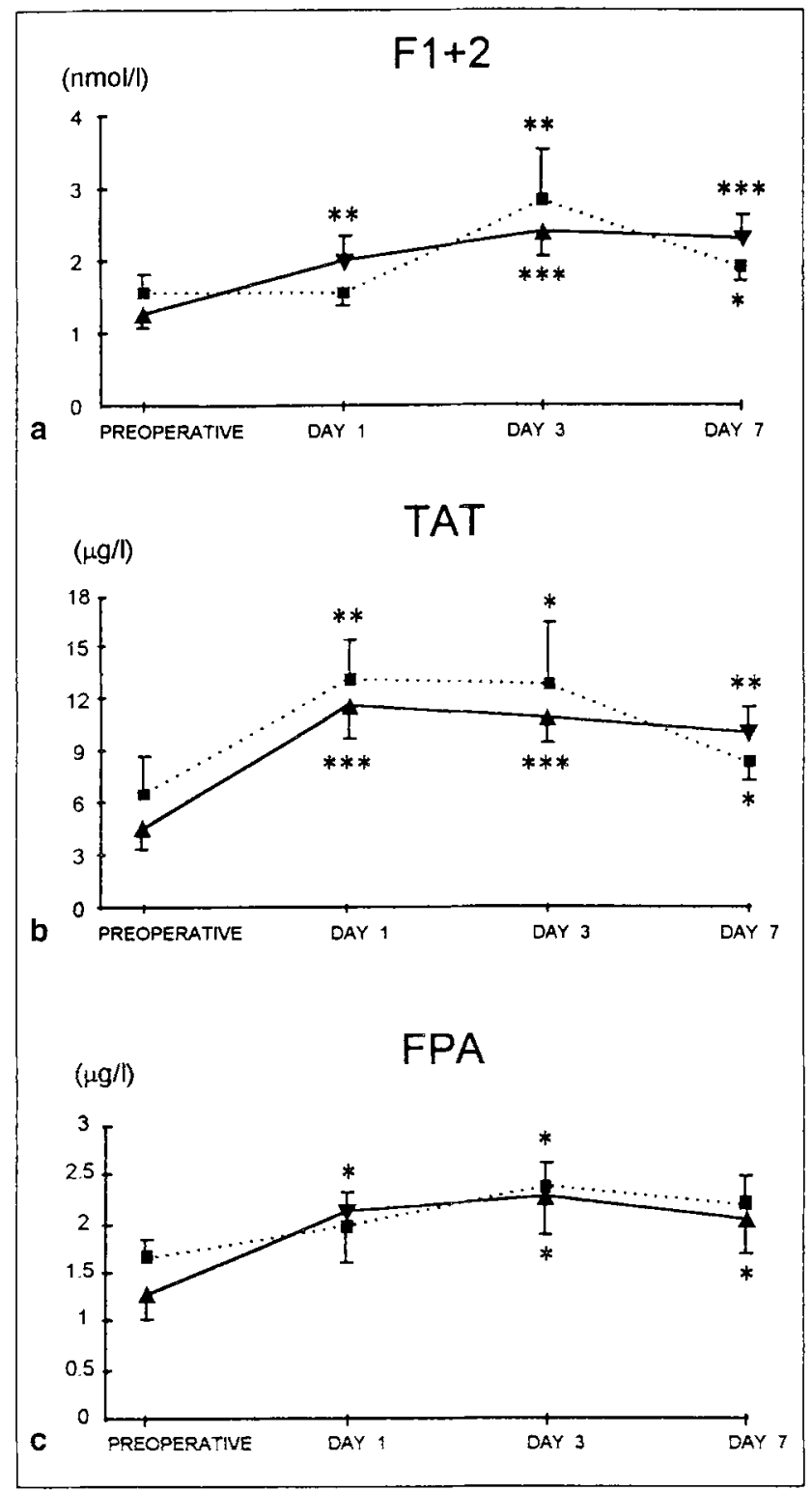

Fig. 1 Evolution of prothrombin fragment $1+2(F l+2)(a)$, thrombin-antithrombin (TAT) complexes (b), and fibrinopeptide A (FPA) (c) throughout the postoperative period in orthopedic (--- -.-) and abdominal (- - -) surgery. Mean \pm SEM is given. * $P<0.05$, ** $P<0.01$, and *** $P<0.0001$ with respect to baseline

tive levels. A similar increase in all clotting markers was observed in both groups with respect to baseline, persisting on day $7(P<0.05)$. Maximum TAT levels were observed on postoperative day 1 in both groups $(P<0.01)$, while $F 1+2$ and FPA showed the highest values on day 3 $(P<0.05)$ in relation to the preoperative levels.

Among the fibrinolytic parameters analyzed we found a significant increase in PAI- 1 activity on postoperative day $1(P<0.05)$ and a decrease on days 3 and 7 in relation to the preoperative levels in both abdominal and orthopedic surgery. A slight reduction of t-PA activity was ob-

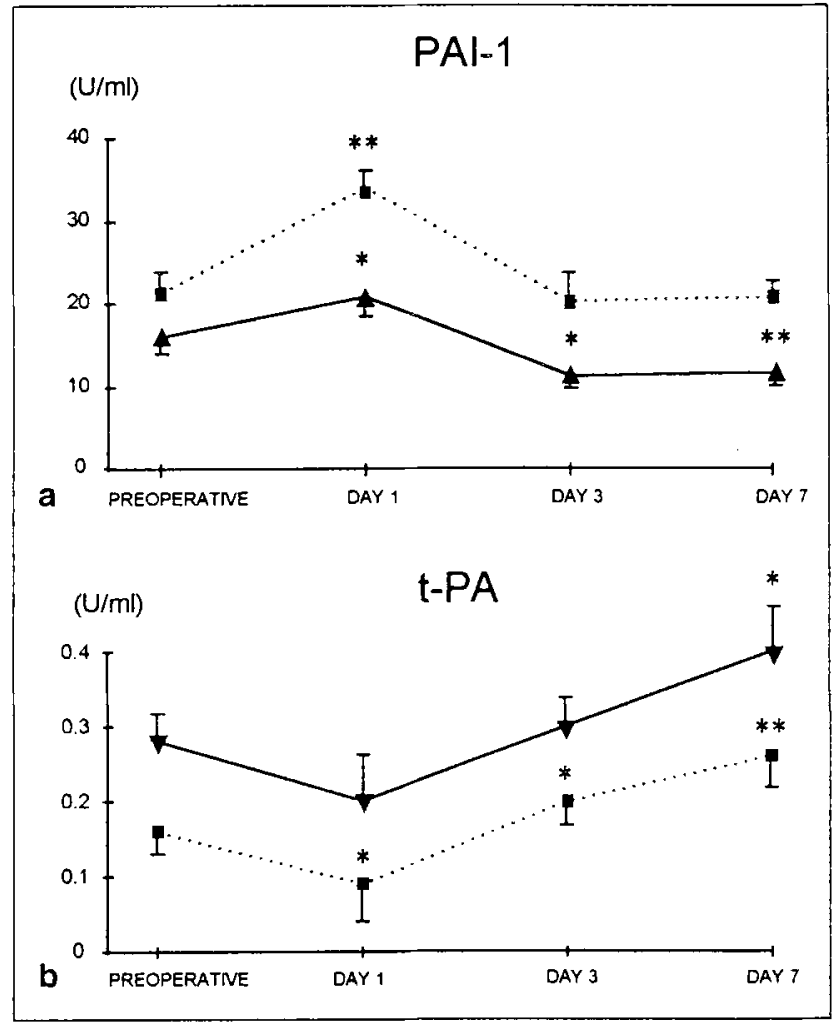

Fig. 2 Evolution of plasminogen activator inhibitor (PAI-l) activity (a) and tissue plasminogen activator $(t-P A)$ (b) throughout the postoperative period in orthopedic ( ...-...) and abdominal ( $-\nabla-)$ surgery. Mean \pm SEM is given. * $P<0.05$ and $* * P<0.01$ with respect to baseline

served early after the operation and this increased significantly on day $7(P<0.05)$ (Fig. 2). The concentration of PAP complexes decreased significantly on day $1(P<0.05)$ compared with preoperative levels in both groups, followed by a marked increase on days 3 and $7 \quad(P<0.01)$ (Fig. 3). No significant differences in the changes could be demonstrated between abdominal and orthopedic surgery.

As shown in Fig. 3, FDP levels increased markedly throughout the postoperative period in both types of surgery $(P<0.05)$, but the generation of FDP was significantly reduced on postoperative day 3 in patients undergoing hip replacement compared with abdominal surgery $(P<0.01)$. Finally, no correlations between the changes in hemostatic parameters and the patients' age were observed.

\section{Discussion}

Sensitive markers for coagulation and fibrinolysis activation were assessed pre- and postoperatively in patients undergoing abdominal and orthopedic surgery. Before surgery no differences in the clotting markers were observed between the groups. However, the PAI-1 activity was higher and t-PA and PAP complexes were lower in patients 


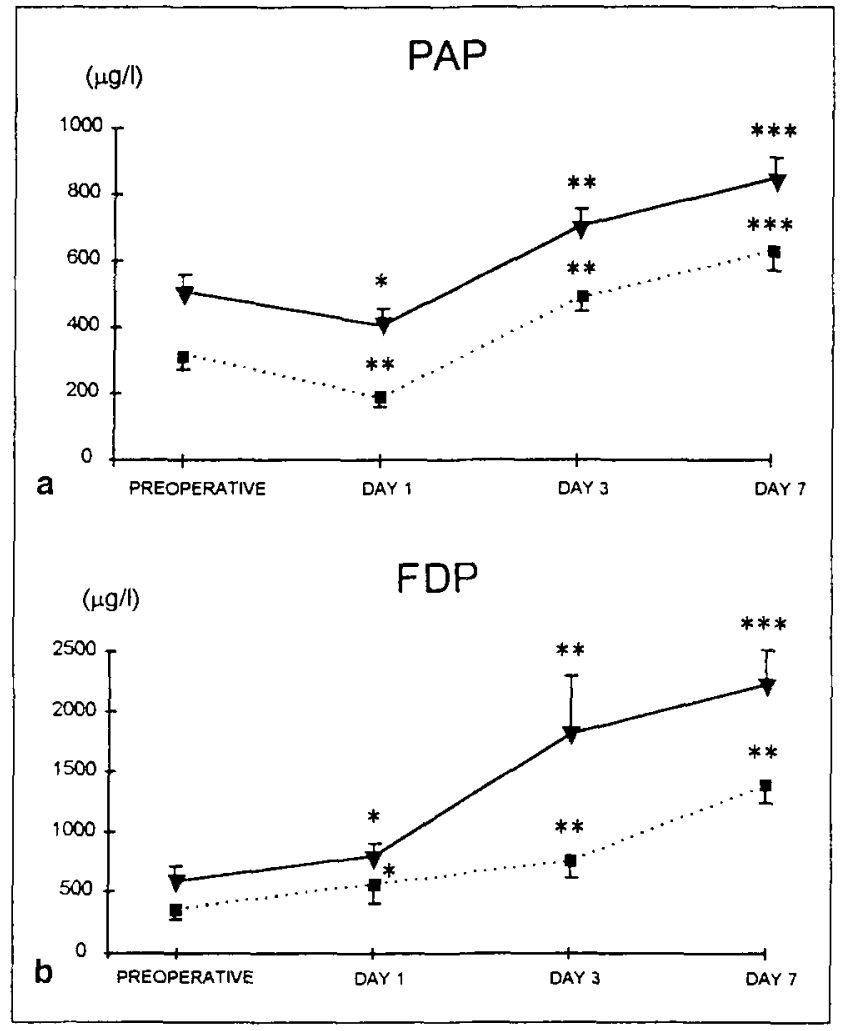

Fig. 3 Evolution of plasmin-antiplasmin (PAP) complexes (a) and fibrin degradation products $(F D P)$ (b) throughout the postoperative period in orthopedic (-.--) and abdominal ( $-\nabla-)$ surgery. Mean \pm SEM is given. * $P<0.05$, ** $P<0.01$, and $* * * P<0.0001$ with respect to baseline

undergoing hip replacement compared with abdominal surgery, suggesting a reduced preoperative fibrinolytic activity in the orthopedic group. It is interesting to note the higher PAI- 1 activity in orthopedic patients, despite the number of cancer patients included in the abdominal group, which is a clinical condition classically associated with an increase in the inhibitor levels [21, 22]. Previous studies have reported a direct relationship between reduced preoperative fibrinolytic activity and the development of postoperative DVT [23]. It has also been demonstrated that PAI- 1 and $\mathrm{t}$-PA levels may be predictive for the development of thromboembolic episodes after different types of surgery [24-26].

A significant increase of all clotting markers during the postoperative period compared with preoperative levels was observed, showing a similar degree of clotting activation in both groups of patients. Our results confirm that a significant activation of the coagulation system takes place after surgery [27]. It has also been suggested that the increase in these clotting markers may be predictive for the development of postoperative thrombosis, thus being useful in the detection of a prethrombotic state after surgery [28].

Impaired fibrinolytic activity characterized by a significant, increase in PAI-1 and a reduction in t-PA was found immediately after operation, followed by a marked inhibitor decrease until day 7 in both types of surgery. Reduced fibrinolytic activity is a well-known feature of the early postoperative state and has been referred to as fibrinolytic shut-down [29-31]. A significant increase in FDP was also found postoperatively in both types of surgery, indicating fibrinolysis activation secondary to fibrin formation and plasmin generation, which was demonstrated by the PAP increase on days 3 and 7 . However, the FDP generation was less evident in patients undergoing hip replacement. Some authors have suggested that FDP levels may be useful for predicting postoperative DVT [32-34]. It is unlikely that the observed fibrinolysis differences between both types of surgery could be attributed to changes induced by the different prophylactic dose, since a clear effect of low molecular weight heparin on fibrinolysis has not been demonstrated in vivo $[35,36]$.

Advanced aged could also account for some of the observed changes indicating activation of the hemostatic mechanism [37]. However, no correlations between the changes in the hemostatic parameters and the patients' age were demonstrated. The levels of the clotting markers remained elevated on day 7 despite prophylaxis with low molecular weight heparin. The possible benefit of prolonged prophylactic treatment on the basis of a reduction in the plasma levels of these markers needs to be carefully evaluated [38].

In conclusion, the impairment of fibrinolysis seems to be more evident in orthopedic than abdominal surgery; this might be an additional risk factor for thrombosis in the former group and might partially explain the different thrombotic tendency between the types of surgery. Additional studies are needed to confirm whether these fibrinolytic differences might be of significance for postoperative thrombosis, using objective diagnostic methods to evaluate DVT.

Acknowledgement Supported by grant 92/0191 from FIS of the Ministery of Health, Spain.

\section{References}

1. Kakkar VV, Howe CT, Flanc C, Clarke MB. Natural history of postoperative deep-vein thrombosis. Lancet 1969; II: 230.

2. Bergqvist D. Post-operative thromboembolism: frequency, etiology and prophylaxis. Berlin Heidelberg New York: Springer. 1983.

3. Bergqvist D. Lindblad B. A 30 year survey of pulmonary embolism verified at autopsy: an analysis of 1274 surgical patients. Br I Surg 1985; 72: 105

4. Warwick D, Williams MH, Bannister GC. Death and thromboembolic disease after total hip replacement. A series of 1162 cases with no routine chemical prophylaxis. J Bone Joint Surg Br 1995; 77:6.

5. Collins R, Scrimgeour A, Yusug S, Phil D, Peto R. Reduction in fatal pulmonary embolism and venous thrombosis by perioperative administration of subcutaneous heparin. Overview of results of randomized trials in general, orthopedic and urologic surgery. N Engl J Med 1988; 318:1162.

6. Clagett GP, Reisch JS. Prevention of venous thromboembolism in general surgical patients. Results of a meta-analysis. Ann Surg 1988; 208: 227. 
7. Kakkar VV. Cohen AT, Edmonson RA, Phillips MJ, Cooper DJ, Das SK, et al. Low molecular weight heparin versus standard heparin for prevention of venous thromboembolism after major abdominal surgery. Lancet 1993: 341:259.

8. Green D, Hirsh J, Heit J, Prins M, Davidson B. Lensing AW. Low molecular weight heparin: a critical analysis of clinical trials. Pharmacol Rev 1994: 46:89.

9. Sue Ling HM, Johnston D, McMakon MJ. Philips PR, Davies JA. Pre-operative identification of patients at high risk of deep venous thrombosis after elective major abdominal surgery. Lancet 1986; I: 1173

10. Nillius AS, Nylander G. Deep vein thrombosis after total hip replacement: a clinical and phlebographic study. Br J Surg 1979; 66: 324

11. Bauer KA, Rosenberg RD. The pathophysiology of the prethrombotic state in humans: insights gained from studies using markers of hemostatic system activation. Blood 1987: 70:343.

12. Mannucci PM, Giangrande PLF. Detection of prethrombotic state due to procoagulant imbalance. Eur $J$ Haematol 1992: 48: 65 .

13. Boisclair MD, Ireland H. Lane DA. Assessment of hypercoagulable states by measurement of activation fragments and peptides. Blood Rev 1990: 4:25.

14. Pelzer H, Schwarz A, Stuber W. Determination of human prothrombin activation fragment $1+2$ in plasma with antibody against a synthetic peptide. Thromb Haemost 1991; 65: 153 .

15. Pelzer H. Schwarz A, Heimburger N. Determination of human thrombin-antithrombin complex in plasma with an enzymelinked immunosorbent assay. Thromb Haemost 1988; 59: 101.

16. Amiral J, Walenga JM, Fareed J. Development of a competitive enzyme immunoassay for fibrinopeptide A. Semin Thromb Hemost 1984; 10:228.

17. Mahmoud M, Gaffney PJ. Bioimmunoassay (BIA) of tissue plasminogen activator (t-PA) and its specific inhibitor (t-PA/INH). Thromb Haemost 1985; 53:356.

18. Chmielewska J, Ranby M. Wiman B. Evidence for a rapid inhibitor to tissue plasminogen activator in plasma. Thromb Res 1983; $31: 427$.

19. Montes R, Páramo JA, Anglés-Cano E, Rocha E. Development and clinical application of a new ELISA assay to determine plas-

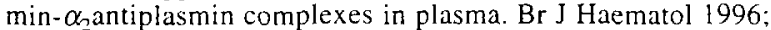
92: $97 \overline{9}$

20. Koppert PW, Hoegee-de Nobel E, Nieuwenhuizen W. A monoclonal antibody-based enzyme immunoassay for fibrin degradation products. Thromb Haemost 1988; 59:310

21. Newland JR, Haire WD. Elevated plasminogen activator inhibitors levels found in patients with malignant conditions. Am J Clin Pathol 1991; 96:602.

22. Foekens JA, Schmitt M, Putten WL van, et al. Plasminogen activator inhibitor- 1 and prognosis in primary breast cancer. J Clin Oncol 1994: 12: 1648.

23. Sue-Ling HM, Johnston D, Verheijen JH, Kluft C. Philips PR, Davies JA. Indicators of depressed fibrinolytic activity in preoperative prediction of deep venous thrombosis. Br J Surg 1987; 74: 275.

24. Rocha E, Alfaro MJ, Páramo JA, Cañadell JM. Preoperative identification of patients at high risk of deep venous thrombosis despite prophylaxis in total hip replacement. Thromb Haemost 1988; 59:93.
25. Eriksson BI, Eriksson E, Gyzander E, Teger-Nilsson AC, Risberg B. Thrombosis after hip replacement. Relationship to the fibrinolytic system. Acta Orthop Scand 1989; 60: 159.

26. Eriksson BI, Eriksson E, Risberg E. Impaired fibrinolysis and postoperative thromboembolism in orthopedic patients. Thromb Res 1991; 62:55.

27. Rahr HB, Sorensen JV, Larsen JF, Jensen FS, Bredahl C. Haemostatic activation before and after surgery in patients with and without gastric malignancy. Thromb Haemost 1994; 71:713

28. Hoek JA, Nurmohamed MT, Cate JW ten, Büller HR, Knipscheer HC, Hamelynck KJ, et al. Thrombin-antithrombin III complexes in the prediction of deep vein thrombosis following total hip replacement. Thromb Haemost 1989; 62: 1050.

29. Aranda A, Páramo JA, Rocha E. Fibrinolytic activity in plasma after gynecological and urological surgery. Haemostasis 1988; 18: 129 .

30. D'Angelo A. Kluft C, Verheijen JH, Rijken DC, Mozzi E, Mannucci PM. Fibrinolytic shut-down after surgery: impairment of the balance between tissue-type plasminogen activator and its specific inhibitor. Eur J Clin Invest 1985; 15:308.

31. Páramo JA, Alfaro MJ, Rocha E. Postoperative changes in the plasmatic levels of tissue-type plasminogen activator and its fast-acting inhibitor. Relationship to deep vein thrombosis and influence of prophylaxis. Thromb Haemost 1985: 54: 713.

32. Rowbotham BJ, Whitaker AN, Harrison J, Murtaugh P, Reasbeck $P$, Bowie EJ. Measurement of crosslinked fibrin derivatives in patients undergoing abdominal surgery: use in the diagnosis of postoperative venous thrombosis. Blood Coagul Fibrinolysis 1992; 3: 25.

33. Bongard O, Wicky J, Peter R, Simonovska S, Vogel JJ, de-Moerloose $P$, et al. D-dimer plasma measurements in patients undergoing major hip surgery: use in the prediction and diagnosis of postoperative proximal vein thrombosis. Thromb Res 1994; 74: 487

34. Dunn ID, Hui AC, Triffitt PD, Crozier AE, Gregg PJ, Sinclair $M E$, et al. Plasma D-dimer as a marker for postoperative deep venous thrombosis. A study after total hip or knee arthroplasty. Thromb Haemost 1994; 72:663.

35. Eriksson E. Wollter IM, Christenson B, Stigendal L, Risberg B. Heparin and fibrinolysis comparison of subcutaneous administration of unfractioned and low-molecular weight heparin. Thromb Haemost 1988; 59:284.

36. Aranda A. Páramo JA. Alfaro MJ, Rocha E. The influence of standard and low molecular weight heparin on fibrinolysis in patients undergoing major abdominal surgery. Biol Clin Hematol 1987; 9: 169

37. Mari D, Mannucci PM, Coppola R, Bottasso B, Bauer KA, Rosenberg RD. Hypercoagulability in centenarians: the paradox of successful aging. Blood 1995; 85:3144.

38. Lojewski B, Bacher $P$, Iqbal O. Walenga JM, Hoppensteadt D. Leya $F$, et al. Evaluation of hemostatic and fibrinolytic alterations associated with daily administration of low molecular weight heparin for a 12 week period. Semin Thromb Haemost $1995 ; 21: 228$ 